\title{
Uma crítica aos indicadores usuais de desindustrialização no Brasil
}

\author{
A critique to the usual economic indicators \\ of de-industrialization in Brazil
}

RICARDO LOBATO TORRES

HENRIQUE CAVALIERI*

RESUMO: O debate sobre desindustrialização ganhou destaque especial no Brasil, mas questões metodológicas relativas aos indicadores econômicos utilizados para avaliar esse processo são raramente discutidos. Este artigo apresenta uma avaliação crítica dos dois indicadores comuns na literatura econômica brasileira: a participação da indústria no PIB e a relação VTI/VBPI. Enquanto a primeira medida mostra oscilações bruscas devido a mudanças na metodologia, a segunda parece ser muito sensível a variações de taxa de câmbio e não captura as diferenças interindústria. Assim, os resultados mostram que ambos os indicadores contêm problemas e podem levar a enganosa conclusões sobre a estrutura produtiva nacional.

PALAVRAS-CHAVE: desindustrialização; doença Holandesa; especialização.

ABSTRACT: A critique to the usual economic indicators of de-industrialization in Brazil. The debate on de-industrialization has gained special prominence in Brazil, but methodological issues concerning the economic indicators used to evaluate this process are rarely discussed. This paper presents a critical evaluation of two common indicators in the Brazilian economic literature: the share of industry in GDP and the ratio VTI/VBPI. While the first measure shows sharp fluctuations due to changes in methodology, the second appears to be very sensitive to exchange rate variations and does not capture the inter-industry differences. Thus, the results show that both indicators contain problems and may lead to misleading conclusions about the national productive structure.

KEYWORDS: de-industrialization, Dutch disease, specialization.

JEL Classification: : L16; E01.

\footnotetext{
* Professor Adjunto do Departamento Acadêmico de Gestão e Economia da Universidade Tecnológica Federal do Paraná, rcd.torres@gmail.com; Doutorando em Economia da Indústria e da Tecnologia pelo Instituto de Economia da Universidade Federal do Rio de Janeiro. E-mail: henrique.cavalieri@gmail. com. Submetido: 28/março/2013; Aprovado: 19/setembro/2014.
} 


\section{INTRODUÇÃO}

O baixo crescimento econômico após a abertura da economia brasileira dos anos 1990 chamou a atenção da sociedade para os possíveis efeitos que a combinação de juros elevados, câmbio sobrevalorizado e redução das tarifas de importações poderiam ter para o desenvolvimento econômico do país. Para alguns economistas, mais do que ter sua capacidade de crescimento limitada, essa tríade levou a uma perda relativa do setor industrial e a uma especialização da produção em setores agroindustriais e de extração mineral. Para outros, no entanto, a indústria brasileira não apenas se reestruturou, em resposta à competição internacional, mas também se modernizou e se fortaleceu, sendo excluídas do mercado apenas as empresas ineficientes, que operavam no país graças à proteção comercial.

A manutenção da tríade nos anos 2000 , em um contexto de avanço da demanda e dos preços internacionais de commodities, bem como do aumento dos deficit comerciais manufatureiros, trouxe novo ensejo às discussões relacionadas à perda de competitividade da indústria nacional, resultando em um amplo debate sobre desindustrialização. Tal debate é travado por economistas das mais diferentes vertentes teóricas, os quais lançam mão de diversos indicadores econômicos para tentar caracterizar as alterações sofridas pela indústria brasileira.

Não obstante o fato de o debate ter evoluído no sentido de melhor definir o termo "desindustrialização", bem como de mapear suas possíveis causas, nota-se que, raramente, questões metodológicas são discutidas a fundo. Como consequência, parte dos resultados apresentados na literatura acadêmica é derivada de indicadores que, frequentemente, estão sujeitos a significativos vieses e pouco representativos da realidade. Como agravante, constata-se também que a política industrial do atual governo - estruturada no Plano Brasil Maior, de 2011 -, estabelece metas baseadas em um indicador enviesado.

O presente trabalho busca contribuir para o debate da desindustrialização a partir de uma avaliação crítica da aplicação de dois indicadores comumente utilizados na literatura: a participação da indústria de transformação no produto interno bruto e a razão entre o valor da transformação industrial e o valor bruto da produção industrial. Enquanto o primeiro é utilizado como a principal medida de desindustrialização, o segundo é visto como uma proxy do adensamento das cadeias produtivas nacionais. Além desta introdução, o artigo contém mais três seções. A segunda seção apresenta o debate acadêmico sobre desindustrialização, sumariando as definições, causas e mensuração desse processo. A terceira seção traz a avaliação daqueles indicadores, focando em questões metodológicas e evidências empíricas. Por fim, fazem-se as conclusões.

\section{DESINDUSTRIALIZAÇÃO: DEFINIÇÃO, CAUSAS E MENSURAÇÃO}

A definição clássica de desindustrialização foi elaborada por Rowthorn e Wells (1987): trata-se da redução permanente da participação da indústria no emprego 
total de uma economia. Dessa definição, deve-se ater o fato de que a desindustrialização é, portanto, uma medida relativa. Na definição de Tregenna (2009), a desindustrialização é a redução da participação da indústria tanto no emprego quanto no produto interno bruto. Considerando essa ampliação do conceito, outra observação deve ser feita: o aumento da produção industrial (produção física) é compatível com a redução na participação da indústria no valor adicionado total da economia. Isso pode ocorrer, por exemplo, se houver mudança nos preços relativos dos produtos industriais vis-à-vis os produtos de outros setores. E, da mesma forma que o emprego, o valor adicionado pela indústria pode crescer a uma taxa menor quando comparado com outros setores da economia, reduzindo, assim, sua participação relativa.

A teoria da desindustrialização de Rowthorn e Wells (1987) explica que, à medida que um país avança em seu processo de industrialização, aumentos de produtividade do setor manufatureiro são obtidos, o que proporciona, assim, a realocação da mão de obra para o setor de serviços. Tal fato decorre, principalmente, da automação da produção com máquinas e equipamentos, do progresso tecnológico e dos ganhos crescentes de escala. Já o setor de serviços é, por natureza, intensivo em recursos humanos, e, portanto, menos produtivo, passando a absorver uma parcela cada vez maior da população economicamente ativa. Em síntese, o crescimento da produtividade na indústria é maior do que nos serviços, portanto a necessidade relativa de emprego de mão de obra é maior no segundo do que no primeiro. Outra razão é que, como o crescimento da produtividade é maior na indústria, ocorre uma mudança nos preços relativos, tornando os produtos industriais mais baratos e liberando renda para o consumo de serviços. A justificativa para que a redução de preços dos produtos industriais não seja plenamente compensada com o aumento do consumo de tais mercadorias é que em países com elevado nível de renda per capita, a elasticidade-renda da demanda por serviços é maior do que por produtos industrializados. Assim, no agregado, o valor adicionado na indústria reduz participação relativa enquanto nos serviços aumenta. Pode-se dizer, portanto, que esse é o processo "natural" de desindustrialização por que uma economia passa à medida que aumenta sua renda per capita.

No entanto, a preocupação no caso brasileiro é que a desindustrialização não seja resultado desse processo "natural”, uma vez que o país ainda não atingiu um nível de renda per capita semelhante ao dos países desenvolvidos. Assim, entende-se que uma redução "precoce" da participação relativa da indústria representa um obstáculo para o desenvolvimento econômico. Essa preocupação decorre do entendimento de que a indústria é um setor dinamizador do crescimento econômico de longo prazo, devido aos seguintes fatores: (1) capacidade de gerar efeitos de encadeamento do produto e do investimento; (2) maior geração e difusão do progresso tecnológico que pode aumentar a produtividade da própria indústria e de outros setores de atividade; (3) economias de escalas estáticas e dinâmicas; (4) maior elasticidade-renda da demanda por seus produtos, aliviando a restrição externa do país exportador de manufaturados (Ferraz, Kupfer e Iooty, 2004; Oreiro e Feijó, 2010). 
A mais conhecida causa da desindustrialização "precoce" é a chamada "doença holandesa", definida como a situação em que a disponibilidade abundante de recursos naturais de um país proporciona vantagens comparativas, de tal forma que a sua extração e exportação leva a superavit comerciais crescentes, tendo como consequência a apreciação cambial. No caso de doença holandesa, o recurso natural tem grande demanda no mercado internacional, fazendo com que os termos de troca se tornem favoráveis, mesmo com sobrevalorização da moeda nacional. Por outro lado, a apreciação cambial inibe os investimentos em indústrias de bens comercializáveis, já que a taxa de câmbio torna os produtos importados mais competitivos. Assim, o crescimento econômico de um país que ainda não tem uma indústria diversificada poderia ser comprometido pela doença holandesa. Para os países que já possuem uma indústria desenvolvida, esta passaria a sofrer intensa competição internacional e apenas alguns tipos de indústrias e serviços de não-comercializáveis se desenvolveriam (Bresser-Pereira, 2008).

Há, ainda, um conceito ampliado de doença holandesa, em que a disponibilidade abundante de recursos humanos também poderia levar um país àquela situação, mas em vez de extração de recursos naturais, a economia especializar-se-ia na produção de artigos industriais comercializáveis intensivos em mão de obra, como as indústrias de vestuário e de calçados. Assim, diferente do caso da Holanda, que experimentou a situação descrita acima após a descoberta de grande reserva de gás natural nos anos 1960 (dando origem ao termo), países como China, Tailândia, Taiwan, entre outros, poderiam sofrer também da doença, mas devido à abundância de mão de obra barata (Bresser-Pereira, 2008). A consequência da doença holandesa seria a reprimarização da economia ou a especialização regressiva, ou seja, concentração da produção em atividades baseadas em recursos naturais, no primeiro caso, ou em atividades específicas, como as manufaturas intensivas em trabalho, no segundo.

A tendência de sobrevalorização cambial não decorre, no entanto, apenas da especialização da pauta exportadora em bens intensivos em recursos naturais ou em recursos humanos de grande demanda no mercado internacional. Bresser-Pereira e Marconi (2010) reconhecem que outros fatores contribuem para a apreciação cambial, alguns de mercado, outros de política econômica, como a adoção de taxa de juros elevadas e abertura da conta de capitais. De fato, Palma (2005) já havia atribuído à radical mudança institucional - das políticas de industrialização por substituição de importação para a abertura econômica - a causa do descolamento entre a participação da indústria no emprego total e o nível de renda per capita na Argentina, Brasil, Uruguai e Chile quando comparados com a trajetória de crescimento econômico dos países desenvolvidos. A esse fenômeno, Palma (2005) denominou de "a nova doença holandesa", que decorre de mudanças na política econômica dos países que aderiram ao "Consenso de Washington". O resultado final da sobrevalorização cambial oriunda de outras fontes que não a exploração das vantagens comparativas no comércio internacional é também o aprofundamento da especialização produtiva.

Para evitar confusão de nomenclatura e para unir esses outros fatores pró- 
-apreciação cambial que Bresser-Pereira e Marconi (2010) e Palma (2005) apresentam, identifica-se aqui uma segunda causa da desindustrialização: o regime macroeconômico, conforme definido por Coutinho (2005). Assim, a doença holandesa é uma causa da desindustrialização quando um país se torna exportador de bens intensivos em recursos naturais ou humanos, acumulando superavit comerciais crescentes e promovendo apreciação cambial. O regime macroeconômico é causa da desindustrialização quando ele gera apreciação cambial via superavit na balança de capital, e quando o país dispõe de vantagens comparativas, o que torna o setor abundante em recursos naturais ou humanos o único competitivo no mercado internacional, desestimulando o desenvolvimento de outros setores industriais. Obviamente, essa distinção teórica não impede que, na prática, ambos os fenômenos sejam observados, nem que um esteja relacionado ao outro. Assim, o fator-chave é a sobrevalorização cambial ocasionada pelos superavit comerciais ou pela balança de capital. A existência das vantagens comparativas em algumas atividades garante a manutenção da competitividade nesses setores específicos e permite a obtenção de elevados superavit comerciais a despeito da apreciação cambial, enquanto que os demais setores perdem participação nas vendas externas, podendo tornar-se deficitários (Oreiro e Feijó, 2010).

Uma terceira causa da desindustrialização é aquela associada ao fechamento de plantas industriais no país, tendo seus produtos substituídos por importação. Isso pode ocorrer, por exemplo, quando empresas nacionais decidem produzir em outros países ou terceirizar parte de sua produção para empresas do exterior, como uma estratégia de aproveitamento das vantagens de custo oferecidas pela liberalização comercial. Assim, tem-se ou a saída de empresas de um país ou a redução da produção e do valor adicionado na indústria nacional. Logo, a expansão da divisão internacional do trabalho - ou a "globalização" - pode ser classificada como a terceira causa de desindustrialização (Palma, 2005).

Uma quarta causa da desindustrialização pode ser atribuída à "ilusão estatística". No caso brasileiro, a primeira possibilidade de ilusão estatística é que, após a abertura econômica, as empresas industriais nacionais sofreram concorrência direta de produtos importados e, para tornarem-se competitivas, realizaram uma reestruturação organizacional, terceirizando atividades não essenciais ao negócio. Parte dessas atividades refere-se à prestação de serviços. Assim, a reestruturação organizacional teria transferido parte do valor da produção e do emprego para o setor de serviços, sem que houvesse, na verdade, redução da produção industrial por tais empresas (Barros e Pereira, 2008). A segunda causa de ilusão estatística seriam as mudanças metodológicas nas formas de apresentação dos dados do Instituto Brasileiro de Geografia e Estatística (IBGE), como possível realocação de empresas antes classificadas como industriais para outros setores de atividade econômica. O Quadro 1 resume as definições e as causas da desindustrialização. 
Quadro 1: Tipos de desindustrialização: definição e causas

\begin{tabular}{|c|l|l|}
\hline \multicolumn{1}{|c|}{ Tipo } & \multicolumn{1}{|c|}{ Definição } & \multicolumn{1}{c|}{ Causas } \\
\hline \multirow{4}{*}{$\begin{array}{c}\text { Desindustrialização } \\
\text { "natural" }\end{array}$} & $\begin{array}{l}\text { Perda relativa de } \\
\text { participação da indústria } \\
\text { no emprego e no PIB com } \\
\text { o crescimento da renda } \\
\text { per capita. }\end{array}$ & $\begin{array}{l}\text { Elasticidade-renda dos serviços torna-se } \\
\text { maior do que dos produtos industriais com } \\
\text { o aumento de renda da população. } \\
\text { Crescimento da produtividade maior na } \\
\text { indústria que nos serviços altera os preços } \\
\text { relativos dos produtos industriais e "libera" } \\
\text { mão de obra. }\end{array}$ \\
\hline \multirow{5}{*}{$\begin{array}{c}\text { Desindustrialização } \\
\text { "precoce" }\end{array}$} & $\begin{array}{l}\text { Perda relativa de } \\
\text { participação da indústria no } \\
\text { emprego e no PIB antes do } \\
\text { crescimento da renda per } \\
\text { capita ao nível do observado } \\
\text { nos países desenvolvidos. }\end{array}$ & $\begin{array}{l}\text { Doença holandesa } \\
\text { Regime Macroeconômico } \\
\text { Globalização produtiva e comercial } \\
\text { Ilusão estatística }\end{array}$ \\
\hline \multicolumn{2}{|l}{} \\
\hline
\end{tabular}

Quanto ao diagnóstico da desindustrialização, pode-se afirmar, de modo geral, que os principais estudos brasileiros têm seus resultados e conclusões influenciados pela maneira como seus respectivos autores entendem por "desindustrialização", mesmo quando a definição não é explicitada. De fato, quando se entende desindustrialização como a perda relativa de capacidade do setor industrial dinamizar a economia, utilizam-se indicadores que buscam aferir, por exemplo, a densidade das cadeias produtivas industriais, a evolução do valor adicionado manufatureiro relativamente ao crescimento do PIB, a composição tecnológica da indústria nacional, os saldos comerciais dos diferentes setores, entre outros. Nesse sentido, os indicadores utilizados são, em geral, valores relativos. Tal abordagem é compartilhada por trabalhos como os de Coutinho (1997), Carneiro (2008), Bresser-Pereira (2009), Oreiro e Feijó (2010) e outros. A partir dessa perspectiva, os resultados obtidos, quando não diagnosticam claramente a existência de desindustrialização, apresentam um tom pessimista em relação ao desenvolvimento do setor industrial brasileiro. As causas apresentadas são geralmente associadas às reformas neoliberais, ao regime macroeconômico e ao crescimento da demanda e dos preços internacionais de commodities exportadas pelo Brasil.

Outra abordagem que também chega a conclusões pessimistas é aquela que compara a evolução da indústria brasileira com a de outros países, sobretudo do leste asiático. A principal conclusão é de que a indústria nacional tem perdido participação em âmbito mundial, sendo uma das causas principais a apreciação cambial, sobretudo no período 2004-2008, como descrito nos trabalhos de Feijó (2007) e Ferraz, Souza e Kupfer (2010).

Por outro lado, quando se associa a desindustrialização a perdas em termos absolutos da produção e exportação industriais, as conclusões são bem distintas. Essa abordagem pode ser encontrada em trabalhos como os de Nassif (2008), Puga (2007) e Barros e Pereira (2008). Nesse sentido, os resultados obtidos mostram geralmente que, apesar de ter ocorrido mudanças estruturais na indústria brasileira desde o final da década de 1980, elas não foram negativas, tendo em vista que 
a produção e a exportação manufatureiras brasileiras têm se expandido em termos absolutos, inclusive em alguns segmentos intensivos em tecnologia. Não obstante o fato de essas conclusões serem bem mais otimistas, a maioria dos autores alerta para o perigo de que, no futuro, tal quadro possa ser revertido, dada, principalmente, a manutenção da apreciação cambial.

Outro argumento que merece destaque é o de Bonelli e Pessôa (2010), que não negam que a indústria brasileira tenha perdido participação relativa no PIB, mas salientam que esse processo esteve condizente a um movimento mundial de perda de participação da indústria. Assim, defendem que o Brasil estava "sobreindustrializado" nos anos 1970, sendo que a trajetória descendente descrita pela participação industrial no produto do país seria um ajuste à norma mundial. Desse modo, esse movimento não seria visto como de desindustrialização, mas sim uma correção do excesso de peso da indústria brasileira resultante do aprofundamento do processo de industrialização por substituição de importações.

Com efeito, verifica-se que muito já se foi discutido sobre se o Brasil está ou não se desindustrializando. Porém, pouco foi feito em termos de questionamento dos principais indicadores utilizados pela literatura para analisar essa questão. Nesse sentido, a próxima seção apresenta uma crítica a alguns desses indicadores.

\section{AVALIAÇÃO DOS PRINCIPAIS INDICADORES DE DESINDUSTRIALIZAÇÃO}

\section{Participação da indústria de transformação no PIB}

Um dos principais indicadores utilizados na literatura é a evolução da participação do valor adicionado da indústria no PIB. Uma trajetória persistente de queda sinalizaria que o setor industrial estaria perdendo importância relativa na geração de renda do país e desempenhando um papel secundário no crescimento econômico nacional. No caso brasileiro, porém, este simples indicador apresenta vieses que impossibilitam a análise de séries históricas. Os vieses decorrem basicamente de dois fatores: mudanças metodológicas sofridas pelas séries de dados e mudanças organizacionais ocorridas no interior da própria indústria.

Em relação às mudanças metodológicas, pode-se constatar dois momentos críticos: 1989-1990 e 1994-1995. Nesses anos ocorreram revisões e modernizações no Sistema de Contas Nacionais, resultando em dificuldade e mesmo em impossibilidade de comparação direta dos dados. No período de 1947 a 1986, a Fundação Getulio Vargas era a responsável pela elaboração das Contas Consolidadas da Nação, um sistema simplificado e mais agregado. A partir de 1986, o IBGE passou a ser o órgão encarregado pela elaboração das Contas Nacionais, sendo que, em 1997, realizou profundas alterações metodológicas, ampliando sua estrutura e modificando as bases de dados, o que possibilitou o lançamento do novo Sistema de Contas Nacionais, em consonância com as recomendações da terceira versão do Manual de Contas Nacionais da Organização das Nações Unidas de 1993. Essa 
alteração resultou na divulgação de uma nova série de dados, abrangendo os anos de 1990 a 1997 e tendo como base de referência o ano de 1985 (Feijó et al., 2008).

Seguindo novamente recomendações de padronização dos órgãos internacionais e visando melhorar a qualidade dos dados fornecidos, as Contas Nacionais passaram por nova revisão em 2007. A base de referência passou a ser o ano de 2000, sendo que foi feita uma retropolação dos dados até 1995. Assim, foram divulgadas novas séries abrangendo o período de 1995 em diante, tendo como referência o ano de 2000. Porém, essa alteração não proporcionou apenas a mudança do ano-base, mas, também, introduziu uma série de transformações, tais como a incorporação de uma nova classificação de produtos e atividades compatível com a Classificação Nacional de Atividades Econômicas (CNAE), o uso de dados das pesquisas setoriais anuais realizadas pelo IBGE (indústria, construção, comércio e serviços) e de dados da Pesquisa de Orçamentos Familiares de 2002 (IBGE, 2012). Nesse sentido, o amplo conjunto de modificações torna a nova série, de 1995 em diante, incompatível com as séries da primeira metade dos anos 1990 (Oreiro e Feijó, 2010), como ilustra o Gráfico 1.

Gráfico 1: Valor adicionado na indústria de transformação

(\% do PIB a preços básicos), Brasil, 1980-2011

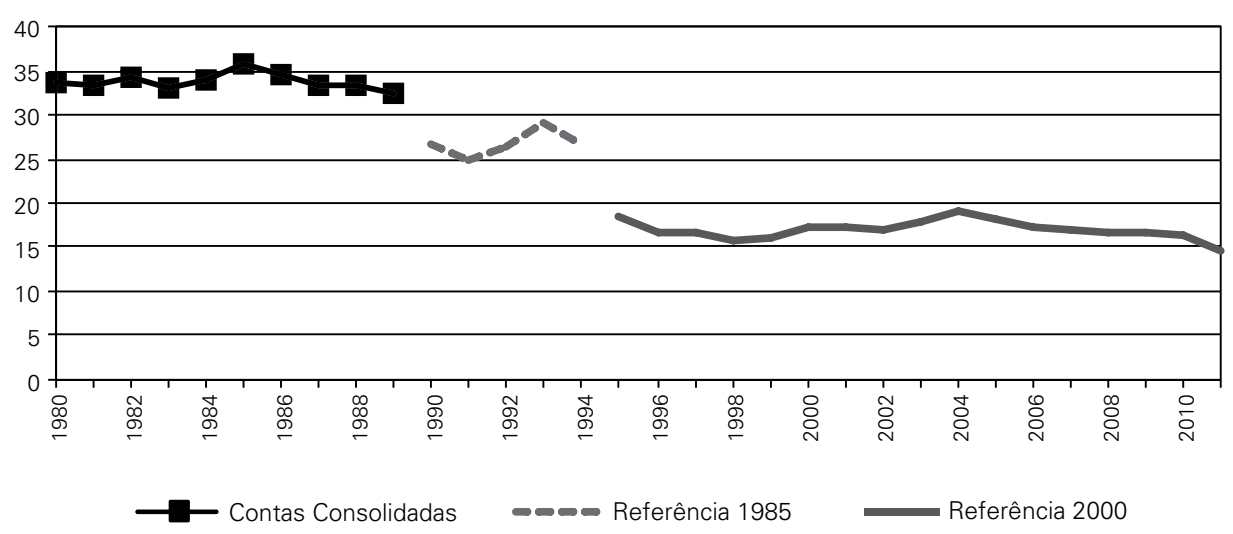

Fonte: Elaboração própria com base nos dados do IPEADATA (1980-2011).

As descontinuidades da série dificilmente poderiam ser explicadas por fenômenos puramente econômicos, já que apresentam quebras de grande magnitude. De 1989 para 1990 a participação da indústria de transformação no PIB diminuiu cerca de seis pontos percentuais (de 32,4\% para 26,5\%), sendo que de 1994 para 1995 a queda é ainda mais drástica, de $26,8 \%$ para $18,6 \%$, quase oito pontos percentuais. Nesse sentido, alerta-se aqui para a inadequação do uso deste indicador para anos anteriores a 1995, fato já ressaltado por Bonelli e Pessôa (2010) e Oreiro e Feijó (2010), o que dificulta a avaliação da desindustrialização no Brasil, já que esta tende a ser um processo estrutural e, portanto, de longo prazo.

Como agravante, houve mudanças na organização produtiva das indústrias que também influenciam esse indicador. Mais especificamente, a terceirização e a 
subcontratação de atividades que antes eram realizadas no interior das empresas industriais resultam na reclassificação dessas atividades para o setor de serviços como exemplo, podem-se citar as atividades de processamento de dados, segurança e limpeza. Assim, não haveria, de fato, a redução do valor e emprego gerados pela economia, mas apenas sua reclassificação na CNAE. Com efeito, de acordo com Ferraz, Kupfer e Iootty (2004), o duplo choque de competição sofrido pela economia brasileira resultante da abertura econômica e adoção de âncora cambial com o Plano Real levou as empresas a adotar novas estratégias, como a subcontratação e a desverticalização da produção, resultando em redução relativa na demanda por trabalhadores na indústria. Cabe ressaltar que essa questão não é específica ao caso brasileiro, tendo em vista que tais alterações na organização industrial estiveram presentes também em países desenvolvidos a partir de 1970, como destacam Rowthorn e Ramaswamy (1997).

Diante disso, torna-se difícil avaliar se a indústria perdeu importância na economia brasileira a partir dos dados disponíveis e, principalmente, apontar a abertura econômica como marco determinante da desindustrialização. Para fazer esse tipo de análise, seria necessário que os dados anteriores à década de 1990 fossem comparáveis com dados posteriores à abertura comercial. Se observados os dados de 1995 a 2011, que estão numa série histórica comparável, não há uma tendência claramente definida. De 1995 a 1998, houve declínio da participação relativa da indústria. De 1999 a 2004, tendência de aumento. E de 2005 a 2011, declínio gradual, com queda mais acentuada no último ano da série. Percebe-se que essas oscilações podem ser flutuações de curto prazo e, de certa forma, podem estar associadas à variação cambial. Nota-se que no período de desvalorização cambial (1999 a 2003), a participação da indústria no PIB é crescente, o que pode ser resultado do aumento de competitividade da indústria no mercado internacional e do consequente aumento da produção para exportação. Essa hipótese, no entanto, deve ser investigada, não sendo objeto de estudo deste artigo.

\section{Adensamento das cadeias produtivas: a razão VTI/VBPI}

A avaliação da densidade das cadeias produtivas industriais mostra-se como uma questão central no que diz respeito ao diagnóstico da desindustrialização. A densidade expressa a capacidade da indústria em agregar valor à produção a partir da distribuição dos diferentes estágios produtivos por elos que compõem a cadeia de produção. À medida que atividades antes realizadas em solo nacional são substituídas por importações, segmentos da estrutura produtiva são perdidos e, junto com eles, os respectivos postos de trabalho e valores adicionados. Assim, esse processo tem como resultado a ampliação do coeficiente importado de insumos industriais e o enfraquecimento dos efeitos multiplicadores do produto.

Acontece que o grau de adensamento das cadeias produtivas é usualmente aferido a partir da razão entre o valor da transformação industrial e o valor bruto da produção industrial - VTI/VBPI. De acordo com a definição do IBGE (2004), o VBPI corresponde ao valor total das vendas de produtos industriais fabricados e 
serviços industriais prestados pela indústria ajustado pela variação de estoques; o VTI, por sua vez, resulta da diferença entre o VBPI e os custos das operações industriais (COI), sendo que estes últimos correspondem ao valor dos custos diretamente envolvidos na produção, tais como matérias-primas utilizadas, consumo de energia elétrica, combustíveis etc. Assim, enquanto o VTI é utilizado como uma proxy do valor adicionado, a razão VTI/VBPI indicaria a parcela da produção nacional que corresponde ao valor de fato agregado pela produção local em comparação ao total produzido. Nas palavras de Feijó, Carvalho e Almeida (2005, p. 19), “quanto menor for essa relação [VTI/VBPI], mais próximo o setor está de uma indústria 'maquiladora' que apenas junta componentes importados praticamente sem gerar valor".

Este indicador tem sido utilizado não apenas no meio acadêmico - como em Feijó, Carvalho e Almeida (2005), Carneiro (2008) e Ferraz, Souza e Kupfer (2010) -, mas também tem pautado as decisões de política industrial do país. O Plano Brasil Maior, lançado em agosto de 2011 e revisado em abril de 2012, apresenta explicitamente como seu foco de atenção maior a inovação tecnológica e o adensamento produtivo. Entre dez metas previstas para serem cumpridas até 2014, duas delas envolvem a razão VTI/VBPI: uma pretende ampliar tal razão para a indústria como um todo para $45,3 \%$ e a outra prevê o aumento desse indicador para os setores específicos ligados à energia para $66 \%$. Conforme o documento, pretende-se "ampliar o valor agregado nacional" e "elevar a participação nacional nos mercados de tecnologias, bens e serviços para energias”, respectivamente (MDIC, 2011).

Porém, tal indicador está sujeito a limitações. Apesar de o adensamento produtivo e a perda de elos das cadeias industriais serem chave para se avaliar a profundidade de um suposto processo de desindustrialização, a razão VTI/VBPI não é um indicador que expressa corretamente essa ideia, uma vez que ela falha tanto numa avaliação setorial intertemporal quanto na comparação intersetorial.

A primeira crítica à razão VTI/VBPI é que ela pode ser sensível às variações na taxa de câmbio. Sendo o VTI uma variável de resíduo, ou seja, calculada pela diferença entre o VBPI e os COI, é possível que, para alguns setores, valorizações cambiais resultem em redução relativa dos COI em função dos menores custos dos insumos importados, sem que haja, necessariamente uma redução do VBPI. Como consequência, o VTI tende a aumentar. Assim, se houvesse um aumento das importações com substituição da produção nacional - um processo que poderia ser caracterizado como de desindustrialização -, obter-se-ia com a análise da razão VTI/ VBPI justamente a conclusão oposta àquela que o indicador se propõe. Pode-se pensar ainda que uma valorização cambial não represente nenhum impacto sobre a estrutura produtiva, ou seja, considerando que as empresas continuem importando somente aquelas mercadorias que habitualmente eram importadas antes da apreciação cambial. Porém, ainda assim, haveria um efeito contábil em função do maior poder de compra da moeda brasileira no mercado internacional, que levaria a uma queda dos COI e a uma elevação na razão VTI/VBPI.

Para verificar a hipótese da influência da taxa de câmbio sobre os COI, analisa-se a relação COI/VBPI e seu comportamento em resposta às variações na taxa de câmbio. A análise do COI como proporção do VBPI se apresenta mais adequa- 
da do que a relação direta dos COI com a taxa de câmbio, pois os COI foram crescentes ao longo dos últimos anos, independentemente das variações na taxa de câmbio, já que a indústria apresentou crescimento positivo. Assim, a relação COI/ VBPI é uma aproximação dos custos por unidade de produto em termos percentuais. Ademais, nota-se que a razão VTI/VBPI é complemento da relação COI/VBPI, sendo a soma de ambos igual a 1, conforme demonstrado na equação abaixo. Assim, a razão VTI/VBPI será maior quanto menor for a razão COI/VBPI e vice-versa.

$$
\frac{V T I}{V B P I}=\frac{V B P I}{V B P I}-\frac{C O I}{V B P I} \Leftrightarrow \frac{V T I}{V B P I}=1-\frac{C O I}{V B P I} \Leftrightarrow 1=\frac{V T I}{V B P I}+\frac{C O I}{V B P I}
$$

O Gráfico 2 apresenta a evolução da relação COI/VBPI e da taxa de câmbio média anual para a indústria de transformação entre 1996 e 2007. A escolha desse período justifica-se pelo fato de os dados da Pesquisa Industrial Anual (PIA) estarem classificados de acordo com a CNAE 1.0, evitando, assim, problemas de comparação por diferenças metodológicas do IBGE a partir de 2008. Ao observar a evolução das duas variáveis, nota-se que a relação COI/VBPI apresenta relação direta com a taxa de câmbio. ${ }^{1}$

Entre 1996 e 2003, a taxa de câmbio passou de uma média anual de 1,01 para 3,08. Na indústria de transformação, nesse período, observa-se uma elevação da relação COI/VBPI de 53,3\% para 57,8\%. No ano de 2004 , a relação COI/ VBPI saltou para $58,9 \%$, reduzindo-se nos anos seguintes, conforme a taxa de câmbio também diminuía. Não se descarta a possibilidade de haver alguma defasagem entre a variação cambial e o impacto sobre os COI, já que os preços podem ser estipulados em contratos com vigência de, pelo menos, um ano e as empresas podem utilizar operações de hedge para se proteger das oscilações cambiais, atenuando ou postergando o impacto da variação cambial para um período futuro. Mas, além disso, outros fatores podem influenciar os COI, como a variação nos preços dos insumos comprados no próprio país. Logo, apesar da correlação significativa entre COI/VBPI e taxa de câmbio, a observação em nível tão agregado não parece adequada para a verificação da hipótese aqui levantada, embora seja um bom indicativo. Isso porque o impacto do câmbio pode ser diferenciado em cada setor industrial.

A taxa de câmbio pode apresentar um efeito maior ou menor em cada setor industrial, a depender da necessidade de importação de insumos em cada um deles e do destino de suas vendas (mercado doméstico ou internacional). Com o objetivo de tornar a análise menos agregada, calculou-se o coeficiente de correlação para cada setor industrial. Para isso, foram utilizados os grupos $\left(3^{\circ}\right.$ nível de desagregação da CNAE) das indústrias extrativas e de transformação, que totalizam 109 setores industriais para os quais se dispõem de dados na PIA. A Tabela 1 resume os resultados obtidos e a participação relativa de cada categoria nos COI, VBPI e VTI.

${ }^{1}$ Coeficiente de correlação $=0,78$, p-valor $=0,0026$. 
Gráfico 2: COI/NBPI (\%) das indústrias de transformação

e taxa de câmbio média anual, Brasil, 1996-2007

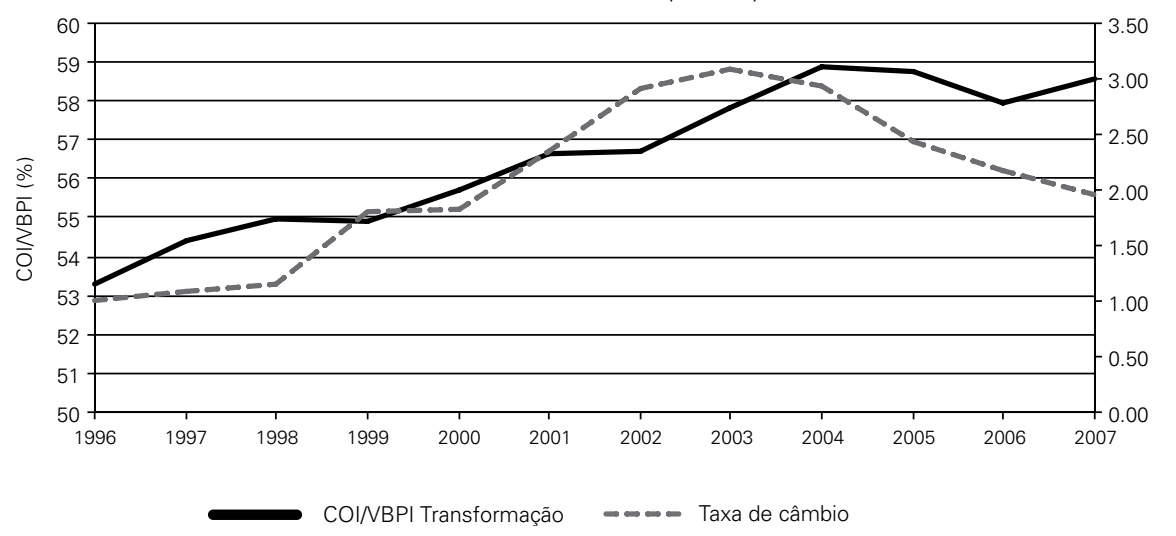

Fonte: Elaboração própria com base nos dados da PIA/IBGE e IPEADATA (1996-2007).

Tabela 1: Frequência e participação relativa de acordo com a correlação COI/VPBI e taxa de câmbio média anual por setores industriais, Brasil, 1996-2007

\begin{tabular}{|l|c|c|c|c|}
\hline \multicolumn{1}{|c|}{ Resultado } & Frequência & $\%$ COI $^{1}$ & $\%$ VBPI & \% VTI $^{1}$ \\
\hline Correlação positiva e significativa & 59 & 56 & 54 & 51 \\
\hline Correlação negativa e significativa & 9 & 12 & 17 & 23 \\
\hline Não significativa & 41 & 31 & 29 & 26 \\
\hline Total & 109 & 100 & 100 & 100 \\
\hline
\end{tabular}

Fonte: Elaboração própria a partir dos dados da PIA/IBGE e IPEADATA (1996-2007).

Nota: ${ }^{1}$ Participação relativa dos setores industriais no total da indústria no ano de 2007.

Os 59 setores industriais que apresentam correlação positiva e significativa representam aqueles setores em que a relação COI/VBPI é diretamente proporcional à variação na taxa de câmbio. Assim, verifica-se que tais setores respondem por $56 \%$ dos COI, 54\% do VBPI e 51\% do VTI. Logo, se esses setores têm os COI influenciados pela taxa de câmbio, quando analisada a razão VTI/VBPI em nível agregado - total da indústria - verifica-se o grande impacto e o erro de interpretação que o uso de tal indicador pode induzir. Além disso, foram identificados nove setores industriais cuja correlação foi negativa e significativa. Assim, somadas essas duas categorias, tem-se que $68 \%$ dos COI sofrem alguma interferência da taxa de câmbio, ampliando o escopo de setores industriais que podem apresentar erro de interpretação quando analisada a razão VTI/VBPI.

Para exemplificar como a razão VTI/VBPI pode gerar uma interpretação equivocada, tome-se o caso da fabricação de produtos farmacêuticos (grupo CNAE 24.5). Estudos mostram que a produção de medicamentos para uso humano no Brasil é fortemente dependente de insumos importados, especialmente farmoquí- 
micos (Fialho, 2005; Vargas, 2009), de forma que variações cambiais impactam diretamente os custos de produção. O Gráfico 3 apresenta a evolução da razão VTI/ VBPI para a fabricação de produtos farmacêuticos no Brasil no período de 1996 a 2007. Em uma interpretação habitual desse indicador, afirmar-se-ia que entre 1996 e 2001 houve redução do valor adicionado por unidade de produto, representando assim perda de elos na cadeia de produção. Já entre 2004 e 2007, afirmar-se-ia que o setor se recuperou, agregando mais valor ao produto final e adensando novamente a cadeia de produção.

Gráfico 3: VTI/NBPI (\%) da produção de produtos farmacêuticos, Brasil, 1996-2007

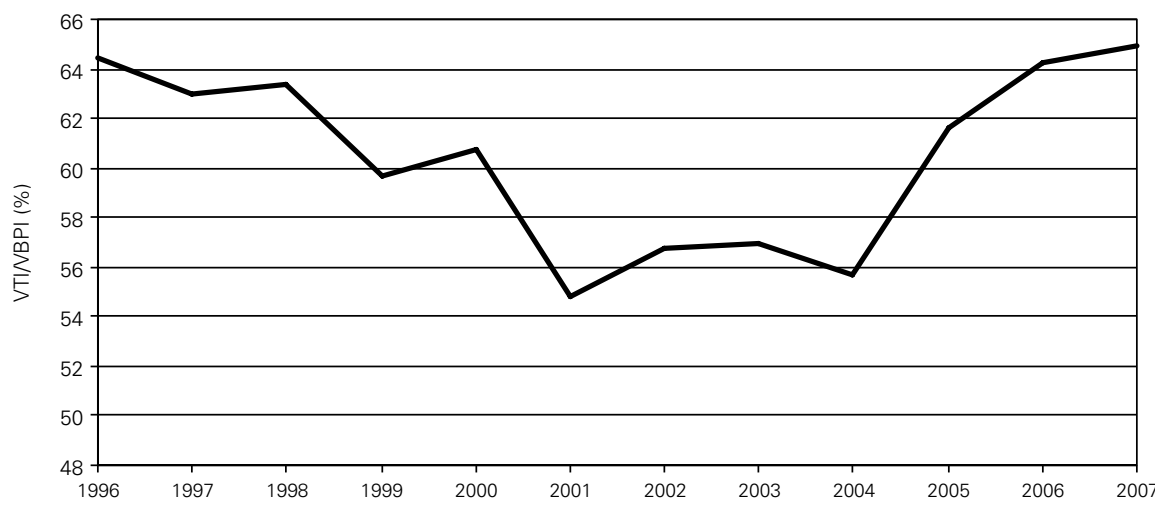

Fonte: Elaboração própria com base nos dados da PIA/IBGE (1996-2007).

Porém, o comportamento da razão VTI/VBPI pode ser visto como reflexo dos movimentos da relação COI/VBPI, mediada pela variação cambial, que afeta diretamente o custo dos farmoquímicos importados. Conforme a Tabela 2, pode-se analisar o comportamento das importações dessa indústria em três períodos: o primeiro, entre 1996 e 1998, o valor das importações se elevou ligeiramente, acompanhando a pequena desvalorização do Real; no segundo, entre 1999 e 2003, há uma forte desvalorização cambial e um baixo crescimento do valor das importações de produtos farmacêuticos; e o terceiro, a partir de 2004, quando o Real passa a valorizar-se e com isso se eleva bruscamente o valor das importações de produtos farmacêuticos. Assim, a interpretação aqui proposta é que a queda da razão VTI/VBPI no período de 1999 a 2003 reflete, na verdade, o aumento relativo dos COI em função da desvalorização cambial. Já no período de 2004 a 2007, a valorização do Real reduziu os COI associados aos produtos importados e tem-se, portanto, um movimento contrário: aumento das importações, redução da relação COI/VBPI e, consequentemente, aumento na razão VTI/VBPI.

A partir disso, não se pode afirmar que houve desindustrialização na indústria farmacêutica no período de 1999 a 2003 e reindustrialização no período de 2004 a 2007. É possível que alterações na estrutura produtiva da indústria tenham ocor- 
Tabela 2: VTI/NBPI, COI/NBPI e valor das importações de produtos farmacêuticos, média dos períodos, Brasil, 1996-2007 (média)

\begin{tabular}{c|c|c|c}
\hline Variável & $1996-1998$ & $1999-2003$ & $2004-2007$ \\
\hline VTINBPI (\%) & 63,6 & 57,8 & 61,6 \\
COINBPI (\%) & 36,4 & 42,2 & 38,4 \\
Valor das importações (US\$ milhões) & 2.046 & 2.408 & 3.552 \\
\hline
\end{tabular}

Fonte: Elaboração própria com base nos dados da PIA/IBGE, SECEX/MDIC e IPEADATA (1996-2007).

rido ao longo dos 12 anos analisados. No entanto, a razão VTI/VBPI pouco pode informar a esse respeito. Sendo uma indústria fortemente dependente de insumos importados e, inclusive, com crescente aumento na importação de medicamentos (bens finais) (Vargas, 2009), a razão VTI/VBPI pode informar, no máximo, a diferença entre os custos e o valor da produção, sem descontar os custos da remuneração do trabalho. Assim, nos períodos de desvalorização cambial, essa diferença diminuiu, porque os custos dos insumos importados aumentaram, enquanto nos períodos de valorização cambial essa diferença aumentou, justamente porque os custos dos insumos importados diminuíram.

A segunda crítica à razão VTI/VBPI é que quando esse indicador é comparado entre os setores industriais, ele não é capaz de informar qual indústria tem uma cadeia de produção mais densa no país, ou seja, aquela que apresenta a maior parte dos elos produtivos localizados em território nacional. Para exemplificar, tomem-se os exemplos das indústrias farmacêutica e automobilística. De acordo com a Tabela 3, a razão VTI/VBPI, em 2005, era de $62 \%$ na indústria farmacêutica e de $27 \%$ na indústria automobilística, sugerindo, na interpretação usual do indicador, que a indústria farmacêutica possui um nível de adensamento maior do que o da indústria automobilística. Ora, ao analisar a história dessas indústrias percebe-se que tal afirmação não reflete a realidade brasileira. A indústria automobilística, desenvolvida principalmente a partir do Plano de Metas, sob o comando do Grupo Executivo da Indústria Automobilística (GEIA), criou as bases, em 1956, para o desenvolvimento da indústria que, apesar de ter o elo da montagem final de veículos formado preponderantemente por empresas estrangeiras, criou uma indústria de autopeças predominantemente nacional. Mesmo com a abertura econômica no início dos anos 1990, políticas foram adotadas para preservar a indústria automobilística nacional, como a criação da Câmara Setorial da Indústria Automobilística, em 1992, e a elaboração do Regime Automotivo Brasileiro, em 1995 (LATINI, 2007). Por outro lado, a indústria farmacêutica sempre foi dependente do exterior, principalmente no tocante aos farmoquímicos. Com a abertura comercial e o acordo TRIPS, não apenas as importações de farmoquímicos aumentaram como também as importações de medicamentos, principalmente com a entrada da Índia no mercado mundial (Guennif e Ramani, 2012). 
Tabela 3: Indicadores selecionados das indústrias farmacêutica e automobilística, Brasil, 2005

\begin{tabular}{l|c|c|c|c|c}
\hline \multicolumn{1}{c|}{ Setor Industrial } & VTI/VBPI & ILT1 $^{1}$ & Posição $^{1}$ & $\begin{array}{c}\mathrm{Cl} 2 \\
\text { (R\$ milhões) }\end{array}$ & $\begin{array}{c}\mathrm{Cl}^{2} \\
\text { (\% importado) }\end{array}$ \\
\hline $\begin{array}{l}\text { Produtos farmacêuticos } \\
\begin{array}{l}\text { Automóveis, caminhonetas } \\
\text { e utilitários }\end{array}\end{array}$ & 62 & 0,88 & 43 & 14.478 & 23 \\
\hline
\end{tabular}

Fonte: Elaboração própria com base nos dados da PIA e Matriz de Insumo-Produto, IBGE (2005).

Notas: 1 Índice de ligação para trás e posição de acordo com esse índice apresentado por Guilhoto e Sesso Filho (2010).

${ }^{2}$ Consumo intermediário.

Se considerados outros indicadores, no entanto, percebe-se que a indústria automobilística no Brasil apresenta uma cadeia produtiva mais densa do que a farmacêutica. Na Tabela 3, são apresentados os índices de ligação para trás de ambos os setores, calculados com base na matriz de insumo-produto de 2005 . Esse índice mostra o nível de encadeamento do setor com outros setores de atividade econômica no que diz respeito ao consumo intermediário. Valores abaixo de $1 \mathrm{e}$ próximos de zero representam pouco encadeamento, quando comparado com a média de todos os setores. Valores acima de 1 representam setores com grande encadeamento relativamente à média dos setores. Ao classificar os 55 setores da matriz insumo-produto de acordo com esse índice, verifica-se que a fabricação de automóveis, caminhonetas e utilitários está na primeira posição, enquanto a fabricação de produtos farmacêuticos encontra-se na $43^{a}$ posição (Guilhoto e Sesso Filho, 2010). Além disso, quando analisados os valores do consumo intermediário, verifica-se que a indústria automobilística brasileira movimenta 3,5 vezes mais os outros setores de atividade do que a indústria farmacêutica, sendo que $18 \%$ desse consumo são atendidos por importações, enquanto na farmacêutica essa proporção é de $23 \%$. Portanto, a razão VTI/VBPI não informa qual dos setores tem a cadeia produtiva mais densa, nem tampouco informa se os insumos de produção estão sendo adquiridos de empresas instaladas no país ou no exterior. Outros dados são necessários, como aqueles apresentados na matriz de insumo-produto.

Utilizando os dados de 2005 para a razão VTI/VBPI e o percentual do consumo intermediário importado no total do consumo intermediário dos 34 setores da indústria de transformação conforme apresentados na matriz de insumo-produto do IBGE, verifica-se que não há relação direta entre essas duas variáveis, conforme Gráfico 4. A partir de tal gráfico, pode-se notar que, por exemplo, tanto o setor de "Fabricação de resina e elastômeros" (ponto A) como o de "Máquinas para escritório e equipamentos de informática" (ponto B) apresentam uma razão VTI/VBPI de cerca de $30 \%$, não obstante o fato de que seus respectivos consumos intermediários importados representarem $9 \%$ e $42 \%$, o que indica grande disparidade em termos de adensamento produtivo para um nível praticamente igual de VTI/VBPI. Assim, a inadequação no uso do VTI/VBPI não se aplica apenas para os exemplos supracitados, mas para os setores da indústria de transformação de forma geral.

A partir do exposto, reconhece-se a dificuldade que os economistas enfrentam para obter um indicador que lhes permita fazer uma correta avaliação das transformações ocorridas na indústria nos últimos anos. No entanto, um esforço de 
(\%) na indústria de transformação, Brasil, 2005

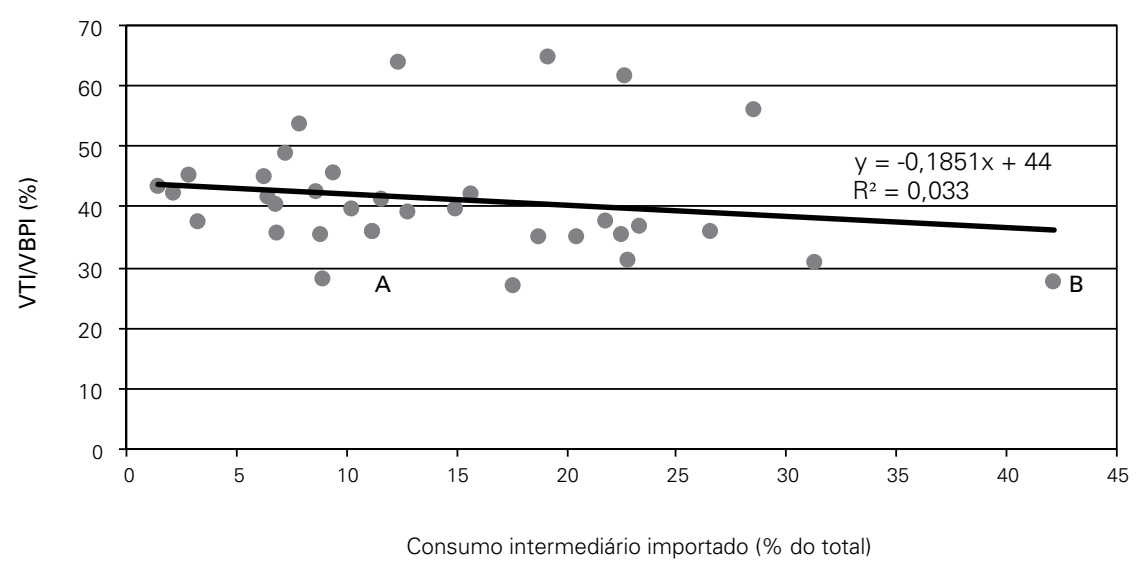

Fonte: Elaboração própria com base nos dados da PIA e da Matriz de Insumo-Produto/IBGE (2005).

analisar criticamente os dados e elaborar indicadores coerentes com a realidade econômica deve ser realizado se se pretende estudar seriamente o tema da desindustrialização no Brasil.

\section{CONSIDERAÇÕES FINAIS}

O debate acadêmico sobre desindustrialização tem ganhado força no Brasil. Apesar de não se haver chegado a um consenso, os estudos conseguiram avançar no esclarecimento do que se entende por "desindustrialização" e quais as suas possíveis causas.

A despeito de tal avanço, constata-se que raramente os trabalhos avaliam criticamente os indicadores utilizados para medir a desindustrialização, o que leva, consequentemente, a interpretações controversas sobre o tema. Possivelmente, as conclusões seriam outras caso tais indicadores fossem questionados. De fato, como foi mostrado, um dos indicadores mais utilizados no debate - a participação do produto industrial no PIB - tem sua trajetória fortemente influenciada por mudanças metodológicas nas Contas Nacionais, de forma que sua série somente pode ser analisada com comparabilidade apropriada a partir de 1995 . O período em questão totaliza 17 anos (1995-2011) e uma análise de caráter estrutural requer uma série de dados para um prazo mais longo. Mais importante ainda é que uma série histórica a partir de 1995 deixa de atender ao propósito de responder uma questão central do debate: o Brasil estaria passando por um processo de perda de sua indústria após a abertura econômica no início dos 1990 e a adoção de um regime macroeconômico pautado em juros altos com consequente valorização cambial? É difícil responder a essa questão com as estatísticas disponíveis, mas isso não signi- 
fica que tal tarefa seja impossibilitada. Portanto, esforços de avaliação crítica dos atuais indicadores e elaboração criativa de novas medidas devem ser conduzidos pelos estudiosos, dada a relevância do tema para a sociedade brasileira.

Atenção especial foi dada, neste trabalho, para a razão VTI/VBPI, a qual, além de ser utilizada no debate acadêmico, figura como meta da atual política industrial (Plano Brasil Maior). Como apresentado, esse indicador falha não apenas ao tentar avaliar se um setor está adensando ou não sua cadeia produtiva ao longo do tempo, mas também tem pouco a dizer na comparação intersetorial.

No primeiro caso, foi visto que o VTI é uma variável de resíduo e, portanto, o seu tamanho é determinado pela diferença entre o VBPI e os COI. Para grande parte da indústria, a razão COI/VBPI apresentou correlação positiva com a taxa de câmbio. Significa dizer que nos períodos de desvalorização cambial, essa razão apresentou-se mais elevada, em função do aumento dos custos dos insumos importados, ao passo que nos períodos de apreciação da moeda nacional, a razão se reduz, justamente pelo barateamento dos insumos importados. Ironicamente, verifica-se, por meio dessa observação, que é possível elevar a razão VTI/VBPI com substituição de parte da produção nacional por importações. Quando extrapolada para a política industrial, verifica-se que é possível atingir as metas com desindustrialização. É claro que um analista atento não observará apenas os dados relativos (VTI/ VBPI), mas também as variações em seus valores absolutos reais.

No segundo caso, verificou-se que esse indicador é inadequado para comparar os setores industriais, já que indústrias com cadeias altamente desenvolvidas podem apresentar uma razão VTI/VBPI baixa e vice-versa. Além disso, existem outros indicadores mais apropriados para esse tipo de análise, como o índice de ligação para trás e o coeficiente de insumos importados. Assim, alerta-se que o uso da razão VTI/VBPI pouco contribui para o debate acadêmico e, o que é mais importante, que a atual política industrial está fixando como meta algo que não expressa seus verdadeiros objetivos. Dessa forma, a adoção desse indicador como parâmetro pode levar à adoção de medidas políticas equivocadas.

\section{REFERÊNCIAS BIBLIOGRÁFICAS}

Barros, Octávio; Pereira, Robson R. (2008) "Desmistificando a tese da desindustrialização: reestruturação da indústria brasileira em uma época de transformações globais” In: Barros, Octávio; Giambiagi, Fabio (Orgs.). Brasil globalizado: o Brasil em um mundo surpreendente. Rio de Janeiro: Campus.

Bonelli, Regis; Pessôa, Samuel A. (2010) "Desindustrialização no Brasil: um resumo da evidência”, Texto para Discussão, Rio de Janeiro: FGV/IBRE.

Bresser-Pereira, Luiz C. (2008) "The Dutch disease and its neutralization: a Ricardian approach", Revista de Economia Política, 28(1): 47-7.

Bresser-Pereira, Luiz C. (2009) Globalização e competição: por que alguns países têm sucesso e outros não. Rio de Janeiro: Elsevier.

Bresser-Pereira, Luiz C.; Marconi, Nelson (2010) “Existe doença holandesa no Brasil?” In: Bresser-Pereira, Luiz C. (Org.). Doença holandesa e indústria. São Paulo: FGV. 
Carneiro, Ricardo (2008) “Impasses do desenvolvimento brasileiro: a questão produtiva”, Textos para Discussão, Campinas: IE/UNICAMP, n. 153, nov.

Coutinho, Luciano (1997) “A especialização regressiva: um balanço do desempenho industrial pós-estabilização” In: Velloso, João. P. R. (Org.). Brasil: desafios de um país em transformação. Rio de Janeiro: José Olympio.

Coutinho, Luciano (2005) "Regimes macroeconômicos e estratégias de negócios: uma política industrial alternativa para o Brasil no século XXI" In: Cassiolato, José E.; Lastres, Helena M. M.; Arroio, Ana (Orgs.). Conhecimento, sistemas de inovação e desenvolvimento. Rio Janeiro: Contraponto.

Feijó, Carmem A. (2007) "Desindustrialização e os dilemas do crescimento econômico recente". Carta do Instituto de Estudos para o Desenvolvimento Industrial, São Paulo, maio.

Feijó, Carmem A. et al. (2008). Contabilidade social: a nova referência das contas nacionais do Brasil. 3 ed. Rio de Janeiro: Campus.

Feijó, Carmem A.; Carvalho, Paulo G. M.; Almeida, Julio S. G. (2005) “Ocorreu uma desindustrialização no Brasil?” Carta do Instituto de Estudos para o Desenvolvimento Industrial, São Paulo, nov.

Ferraz, João. C.; Kupfer, David; Iootty, Mariana (2004) “Competitividad Industrial en Brasil 10 años después de la liberalización”, Revista de la CEPAL, 82: 91-119.

Ferraz, João C.; Souza, Francisco E. P.; Kupfer, David (2010) “Trayectorias para el desarrollo brasileño", Boletín Informativo Techint, n. 333, p.39-54, set.-dez.

Fialho, Beatriz C. (2005) Dependência tecnológica e biodiversidade: um estudo histórico sobre a indústria farmacêutica no Brasil e nos Estados Unidos. 2005. 224 f. Tese (Doutorado em Engenharia de Produção) - Instituto Alberto Luiz Coimbra de Pós-Graduação e Pesquisa em Engenharia, Universidade Federal do Rio de Janeiro, Rio de Janeiro.

Guennif, Samira; Ramani, Shyama V. (2012) "Explaining divergence in catching-up in pharma between India and Brazil using the NSI framework", Research Policy, 41: 430-441.

Guilhoto, Joaquim J. M.; Sesso Filho, Umberto A. (2010) "Estimação da matriz insumo-produto utilizando dados preliminares das contas nacionais: aplicação e análise de indicadores econômicos para o Brasil em 2005”, Economia \& Tecnologia, 6 (23): 53-62.

IBGE, Diretoria de Pesquisa - DPE, Coordenação de Contas Nacionais - CONAC, Sistema de Contas Nacionais - Brasil Referência 2000. Nota metodológica no. 1, Apresentação da Nova Série do Sistema de Contas Nacionais, referência 2000. Disponível em <www.ibge.gov.br>. Acesso em 6 jun. 2012.

IBGE - Instituto Brasileiro de Geografia e Estatística (2004) Pesquisa Industrial anual - empresas. Série Relatórios Metodológicos, v. 26. Rio de Janeiro.

Latini, Sidney A. A. (2007). A implantação da indústria automobilística no Brasil: da substituição de importações ativa à globalização passiva. São Paulo: Alaúde Editorial.

MDIC - Ministério do Desenvolvimento, Indústria e Comércio Exterior (2011) "Brasil Maior: inovar para competir, competir para crescer. Plano 2011/2014”. Disponível em: <http://www.brasilmaior.mdic.gov.br>. Acesso em 20 jun. 2012.

Nassif, André (2008) “Há evidências de desindustrialização no Brasil?”, Revista de Economia Política, 28 (1): 72-96.

Oreiro, José L.; Feijó, Carmem A. (2010) “Desindustrialização: conceituação, causas, efeitos e o caso brasileiro”, Revista de Economia Política, 30 (2): 219-232.

Palma, José G. (2005) “Quatro fontes de 'desindustrialização’ e um novo conceito de doença holandesa”, Conferência de Industrialização, Desindustrialização e Desenvolvimento organizada pela FIESP e IEDI. Disponível em: <http://www.fiesp.com.br/download/semin_desindustrializ/1aPalm aQuatrofontesda desindustrializ.pdf> Acesso em 18 ago. 2011.

Puga, Fernando P. (2007) “Aumento das importações não gerou desindustrialização”, Visão do Desenvolvimento, BNDES, Rio de Janeiro, 26: 1-8.

Rowthorn, Robert; Ramaswamy, Ramana (1997) “Deindustrialization: causes and implications”, IMF Working Paper, 42: 1-38. 
Rowthorn, Robert; Wells, John (1987) De-industrialization and foreign trade. Cambridge: Cambridge University Press.

Tregenna, Fiona (2009) "Characterizing deindustrialization: an analysis of changes in manufacturing employment and output internationally", Cambridge Journal of Economics, 33 (3): 433-466.

Vargas, Marco A. (2011) “Documento Setorial: Farmacêutica”. In: Kupfer, David; Laplane, Mariano F.; Hiratuka, Célio (coord.). Perspectivas de investimento no Brasil: sistema produtivo da saúde. v.11. Rio de Janeiro: Synergia Editora. 